\title{
DELINEATION WATER OF PEARL RIVER BASIN USING LANDSAT IMAGES FROM GOOGLE EARTH ENGINE
}

\author{
Bi Lu${ }^{1}$, Fu Bolin ${ }^{1}$, Lou Peiqing ${ }^{1}$, Tang Tingyuan ${ }^{1}$ \\ ${ }^{1}$ College of Geomatics and Geoinformation, Guilin University of Technology, Yanshan Street, Guilin - (bilu1017, fbl2012, gislou, \\ TangtyRS)@126.com
}

Commission VI, WG VI/4

KEY WORDS: Pearl River Basin, Water index, Google Earth Engine, Threshold segmentation, Landsat images

\begin{abstract}
:
Surface water plays an important role in ecological circulation. Global climate change and urbanization affect the distribution and quality of water. In order to obtain surface water information quickly and accurately, this study uses Google Earth Engine (GEE) as a data processing tool, 309 Landsat 8 series images from 2016 to 2019 are selected to calculate 4 different water indexes, including

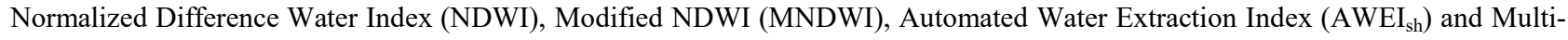
Band Water Index (MBWI) to extract surface water in Pearl River Basin. In order to remove the influence of other ground objects, Normalized Vegetation Index (NDVI), Normalized Difference Building Index (NDBI) and Digital Surface Model (DSM) are combined with the above four water indexes, and threshold segmentation is used to eliminate the influence of vegetation, buildings and mountains. Finally, take the advantage of morphological filtering algorithm to eliminate non-water pixels. The results show that GEE is able to extract surface water in a very short time; $\mathrm{AWEI}_{\mathrm{sh}}$ has the highest overall accuracy of $94.12 \%$, which is $7.20 \%$ higher than the classical NDWI method; There is no significant difference in the width and shape of rivers from 2015 to 2018 ; The locations of the rivers extracted by the four methods are consistent with the 1: 100,000 river system basic data of 2015 provided by the Ministry of Water Resources of the People's Republic of China.
\end{abstract}

\section{INTRODUCTION}

Water is the basis of material exchange in the earth's ecosystem and an indispensable important resource for human production and life. In recent years, the issue of water resources has become a hot topic of research. Extraction of water information is of great significance for rational allocation of water resources, prevention of flood disasters, and assessment and prediction of environmental ecological health. China has a vast territory and uneven distribution of water resources. Traditional water measurement methods are inefficient and costly and cannot meet the requirements of the big data era. Remote sensing technology has become the main means to obtain surface information due to its advantages of wide range, short period and abundant surface information (Xin et al., 2016). With the improvement of the resolution of remote sensing satellite images, the ground object information becomes more and more diversified and clear. Remote sensing technology has been widely used in information extraction (Acharya et al., 2019; Bahrawi and Elhag, 2019), disaster monitoring (Fan et al.,2016; Vishnu et al., 2019) and crop prediction (Dong et al., 2016).

Scholars have done a lot of research on water identification and extraction using remote sensing technology. In 1996, Mcfeeters proposed normalized water body index (NDWI) to identify water information (McFeeters, 1996). Nine years later, Xu Hanqiu improved on the basis of NDWI, replacing near-infrared band with mid-infrared band, and proposed Modified NDWI (MNDWI) (Xu, 2005), which effectively removed the influence of buildings and further improved the accuracy of water extraction. Zhitian Deng et al (Deng et al., 2019) used Landsat 8 OLI image and adopted a gray-based water body identification method to extract water bodies in the Bohai Sea region of China.
The results show that the None-Radiation-Calibration Water Index is more suitable for nearshore and estuarine areas. Andrew Ogilvie and others (Ogilvie et al., 2018) used Landsat images to monitor small reservoirs in the Merguellil Upper Catchment Located in Central Semi-Arid Tunisia in the semiarid region of central Tunisia, indicating that remote sensing technology can also effectively identify small areas of water. In addition, remote sensing technology also has some applications in high altitude areas. ZHANG Mei-mei proposed a method of combining threshold segmentation with nonlocal active contour algorithm (Zhang et al., 2018), which has detected large areas of glacial lakes $\left(26^{\circ}-45^{\circ} \mathrm{N}, 67^{\circ}-105^{\circ} \mathrm{E}\right)$ in Asia. it is found that this method is very effective for glacier identification in high mountain areas and is of great significance for further exploration of ice and snow areas and coping with climate change.

Although the above remote sensing method can effectively identify and extract water bodies, the traditional remote sensing image processing software has limited computing power, small amount of data and low efficiency in dealing with large areas. GEE meets the requirements of big data era well, it is a cloud computing platform for global scale online processing, analysis and visualization of massive geoscience data sets (especially remote sensing image data), which can process a large number of satellite images quickly in a very short time (Gorelick et al., 2017). GEE owns a collection of remote sensing images with a history of more than 40 years, including Landsat, Sentinel, MODIS and other high-resolution images, such as the 1-meter resolution U.S. aerial image data provided by the US National Agriculture Imagery Program (NAIP), and adds about 4,000 images per day. Users can easily call or download them online. By using JavaScript API provided by GEE, Web services based 
on Google Earth Engine and Google Cloud can be quickly established to realize urban land expansion monitoring (Sun et al., 2019), global water resources change monitoring (Pekel et al., 2016), forest time series change analysis (Chen et al., 2017; Hansen et al., 2013), disaster management and earth science(Onisimo and Lalit, 2019; Sazib et al., 2018). In addition, GEE is a cloud-based geospatial processing platform, and data don't need to be downloaded for operation and calculation, thus avoiding the problem of insufficient storage space for traditional software.

Climate change intensifies the severity and variability of drought in the Pearl River Basin (Wang et al.,2018). As the urbanization and the population increases, the Pearl River Delta is facing the problem of water shortage (Liu et al.,2017). This research adopts the method of extracting surface water in Pearl River Basin based on GEE platform. Firstly, obtain Landsat 8 images from GEE to calculate four water indexes, including $A W E I_{\mathrm{sh}}, \mathrm{MBWI}, \mathrm{MNDWI}$ and NDWI to preliminarily distinguishes water and non-water through threshold segmentation. Then removes the influences of mountain shadow, vegetation and buildings respectively by combining with Digital Surface Model (DSM), NDVI and NDBI. Finally, further removes non-water pixels according to morphological corrosion and expansion algorithm, and realizes fine extraction of water by comparing the advantages and disadvantages of the four kinds of water indexes. In the verification stage, 400 sample points are randomly generated from the extraction results to verify the extraction accuracy of the river. Compared with the existing water products from Ministry of Water Resources, the continuity and the geometric accuracy of extracted rivers are verified from the upper, middle and lower reaches of the Pearl River basin respectively.

\section{METHOD AND MATERIALS}

\subsection{Method}

Spectral difference is an important foundation to successfully discern water from non-water surfaces. In the data preprocessing stage, the multi-band image with a resolution of $30 \mathrm{~m}$ and the panchromatic image are fused to obtain a $15 \mathrm{~m}$ high-resolution image which is easy to interpret. Then NDWI (McFeeters, 1996), MNDWI (Xu, 2005), MBWI (Wang et al., 2018) and $A W E I_{\text {sh }}$ (Feyisa et al., 2014) are used to extract water. Combined with NDVI and NDBI, vegetation and building shadow are removed by threshold segmentation. Because the spectral characteristics of hillshade are very similar to water and easy to be confused, Digital Surface Model is added to remove the influence of hillshade according to the physical characteristics of water. For the problems of incomplete small water, non-water pixel misclassification and discontinuous linear water, morphological expansion and corrosion methods are adopted to fix (Figure 1).

$$
\begin{gathered}
N D W I=\frac{G-N I R}{G+N I R} \\
M N D W I=\frac{G-M I R}{G+M I R} \\
A W E I_{s h}=B+0.25 G-1.5\left(N I R+S W R_{1}\right)-0.25 S W R_{2}
\end{gathered}
$$

$$
\begin{gathered}
M B W I=2 G-R-N I R-S W I R_{1}-S W I R_{2} \\
N D V I=\frac{N I R-R}{N I R+R} \\
N D B I=\frac{S W I R_{1}-N I R}{S W I R_{1}+N I R}
\end{gathered}
$$

where G, NIR, MIR respectively corresponding to bands 3, 5 and 6 of Landsat 8 images, and R, SWIR1, SWIR 2 respectively corresponding to bands 4,7 and 7 of Landsat 8 images.

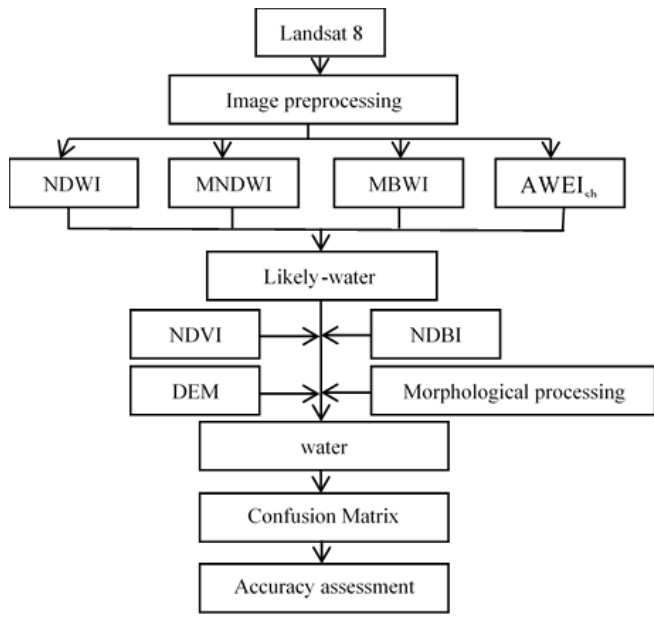

Figure 1. Methodology flowchart

\subsection{Materials}

2.2.1 Study area: The Pearl River Basin $\left(102^{\circ} 14^{\prime} \sim\right.$ $\left.115^{\circ} 53^{\prime} \mathrm{E}, 21^{\circ} 31^{\prime} \sim 26^{\circ} 49^{\prime} \mathrm{N}\right)$ is located in southern China, spanning 8 provinces (autonomous regions) including Yunnan, Guizhou, Guangxi, Guangdong, Hunan, Jiangxi, Fujian, Hainan and Hong Kong and Macao Special Administrative Regions. The basin covers an area of 453,700 square kilometers and is mainly composed of Xijiang River, Beijiang River, Dongjiang River and Pearl River Delta. Pearl River is the second largest river in China. Its main stream is Xijiang River, which originates from Mount Ma Xiong of the Wumeng mountain system in the Yunnan-Guizhou plateau. The area of Xijiang River accounts for $77.8 \%$ of the whole basin area (Su and Chen, 2019).

The Pearl River Basin is located in a tropical and subtropical climate region, with humid heat and rainy (Liu et al., 2013), annual average runoff of 338.1 billion cubic meters, and annual average total water resources of 520.1 billion cubic meters, accounting for $18.3 \%$ of the country. However, the temporal and spatial distribution of rainfall is uneven, mainly occurring in the east, gradually decreasing from east to west.

The Pearl River Basin has mild climate and favorable geographical conditions. There are three basic geomorphological types distributed in the basin, including mountain, hill and plain, of which mountain and hill account for $94.5 \%$ of the total area of the basin. Rich mineral resources, good shipping conditions and abundant fishery resources in the basin promote the sustained and rapid growth of the national economy in the pearl river basin, but the economic development 
is uneven. The upstream areas such as Yunnan and Guangxi are experiencing slow economic development, while the downstream pearl river delta experienced large-scale land reclamation in the late $1980 \mathrm{~s}$, resulting in an exponential growth in social economy (Ranasinghe et al., 2019).

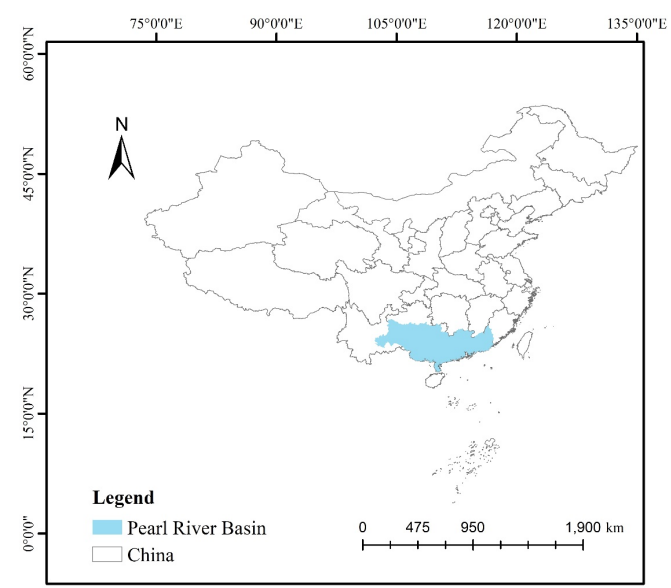

Figure 2. Location of the Pearl River Basin

2.2.2 Data: 309 Landsat 8 top-of-atmosphere reflectance (TOA) images from United States Geological Survey (USGS) are acquired on GEE, with a time span of January 1, 2016 to April 10, 2019, and cloud cover less than $10 \%$. Landsat is a part of the USGS National Land Imaging (NLI) Program, with a spatial resolution of $30 \mathrm{~m}$ for Band 1 -Band 7 and $15 \mathrm{~m}$ for panchromatic band (Band8). The horizontal resolution of $30 \mathrm{~m}$ ALOS Global Digital Surface Model (DSM) data is acquired by JAXA Earth Observation Research Center, the dataset is based on the DSM dataset (5-meter mesh version) of the World 3D Topographic Data. In addition, the vector data of the rivers used for verification come from the basic data of 1: 100000 river systems of the Ministry of Water Resources in 2015. The sample points are generated from Google earth Pro. In this study, 200 water and 200 non-water sample points are randomly and evenly selected for accuracy verification.

\begin{tabular}{|c|c|c|}
\hline Number & $\begin{array}{c}\text { ImageCollection } \\
\text { ID }\end{array}$ & Provider \\
\hline \multirow{2}{*}{1} & $\begin{array}{c}\text { LANDSAT/LC0 } \\
\text { 8/C01/T1_RT_T } \\
\text { OA }\end{array}$ & USGS/Google \\
\hline 2 & $\begin{array}{c}\text { JAXA/ALOS/A } \\
\text { W3D30_V1_1 }\end{array}$ & $\begin{array}{c}\text { JAXA Earth Observation } \\
\text { Research Center }\end{array}$ \\
\hline
\end{tabular}

Table 1. The source of imagecollection

\section{RESULTS}

\subsection{Classification accuracy}

200 water sample points and 200 non-water sample points were randomly and evenly selected from Google Earth Pro to calculate the confusion matrix, and then analysis the overall classification accuracy, Kappa coefficient and total error of water. Water commission error means that non-water pixels are labeled as water, similarly, water commission error means that water is marked as non-water pixels (Wang et al., 2018; Feyisa et al., 2014).
The accuracy of extracting water by different water indexes is shown in Table 2. Obviously, overall classification accuracy of $\mathrm{AWEI}_{\mathrm{sh}}$ is the highest among the four water indexes, reaching $94.12 \%, 7.20 \%$ higher than NDWI, and the misclassification rate is only $44.95 \%$ of NDWI, while the overall classification accuracy of MBWI and MNDWI are between the above two, $91.9392 .81 \%$ and $91.50 \%$, respectively.

In order to test the accuracy of water extraction, three different regions in the upper, middle and lower reaches of the Pearl River Basin are chosen respectively to verify, with Shilong as the dividing point in the middle and upper reaches and Wuzhou as the dividing point in the middle and lower reaches. The Junction of two major rivers, namely Nanpan River and Hongshui River, is selected in the upper reaches, a part of Xijiang River in Zhaoqing City, Guangdong Province with small tributaries is intercepted in the middle reaches, and a planar water named Gongping reservoir, is a verification area in the lower reaches. The blue part in figure 3 indicates water, which can be clearly seen from the upstream that compared with other methods, the river extracted by $\mathrm{AWEI}_{\mathrm{sh}}$ method maintains relatively complete water information, and it's continuity is better than others. On the contrary, rivers extracted by MNDWI and NDWI has obvious interruption, and the small rivers cannot be identified. In the middle reaches, we can see that $\mathrm{AWEI}_{\mathrm{sh}}$ is more effective in extracting small tributaries, and buildings are effectively removed, and more importantly, it has a high degree of coincidence with the true color composite image. For planar water bodies, there is no obvious difference in the results of the four water indexes. To sum up, $\mathrm{AWEI}_{\mathrm{sh}}$ is superior to the other three methods with higher accuracy and smaller misclassification rate, and its Kappa coefficient is $88.24 \%$.

\section{2 geometric accuracy}

As AWEI has the highest accuracy, three regions in the upper, middle and lower reaches of the Pearl River Basin are selected respectively in the results of $A W E I_{\text {sh }}$ to superimpose with the 1: 100,000 river system basic data to further verify the geometric accuracy of rivers. Wanfeng Lake, the junction of Xijiang River and Hejiang River and the junction of Dongjiang River and Xizhi River are respectively the representative regions in the upper, middle and lower reaches of the Pearl River Basin for verification. In the following figure, the black outline represents the 2018 Pearl River Basin river vector extracted in this study, and the red outline represents the existing vector diagram in 2015.

The following figures shows that the center line of the river extracted in this study is consistent with the existing basic river data, but the river width is varying more or less. From 2015 to 2018, the number and area of small tributaries of Wanfeng Lake increased (fig. 4). Except for very small rivers, the method of this study can extract most rivers, and remove hillshade and building shadow effectively, which are not easily distinguished from water (fig. 5). From 2015 to 2018, the width of some rivers at the junction of Dongjiang River and Xizhijiang River was reduced. Islands in the river, as long as reservoirs and lakes around the river can also be identified with correct geometric positions (fig. 6).

In order to compare the river widths in 2015 and 2018, 148 river widths in the Pearl River Basin are randomly measured. The scatter diagram (fig. 7) fluctuate slightly, but show a generally linear relationship, which meant that rivers in the 
Pearl River Basin had not changed much during the three years and remained stable overall.

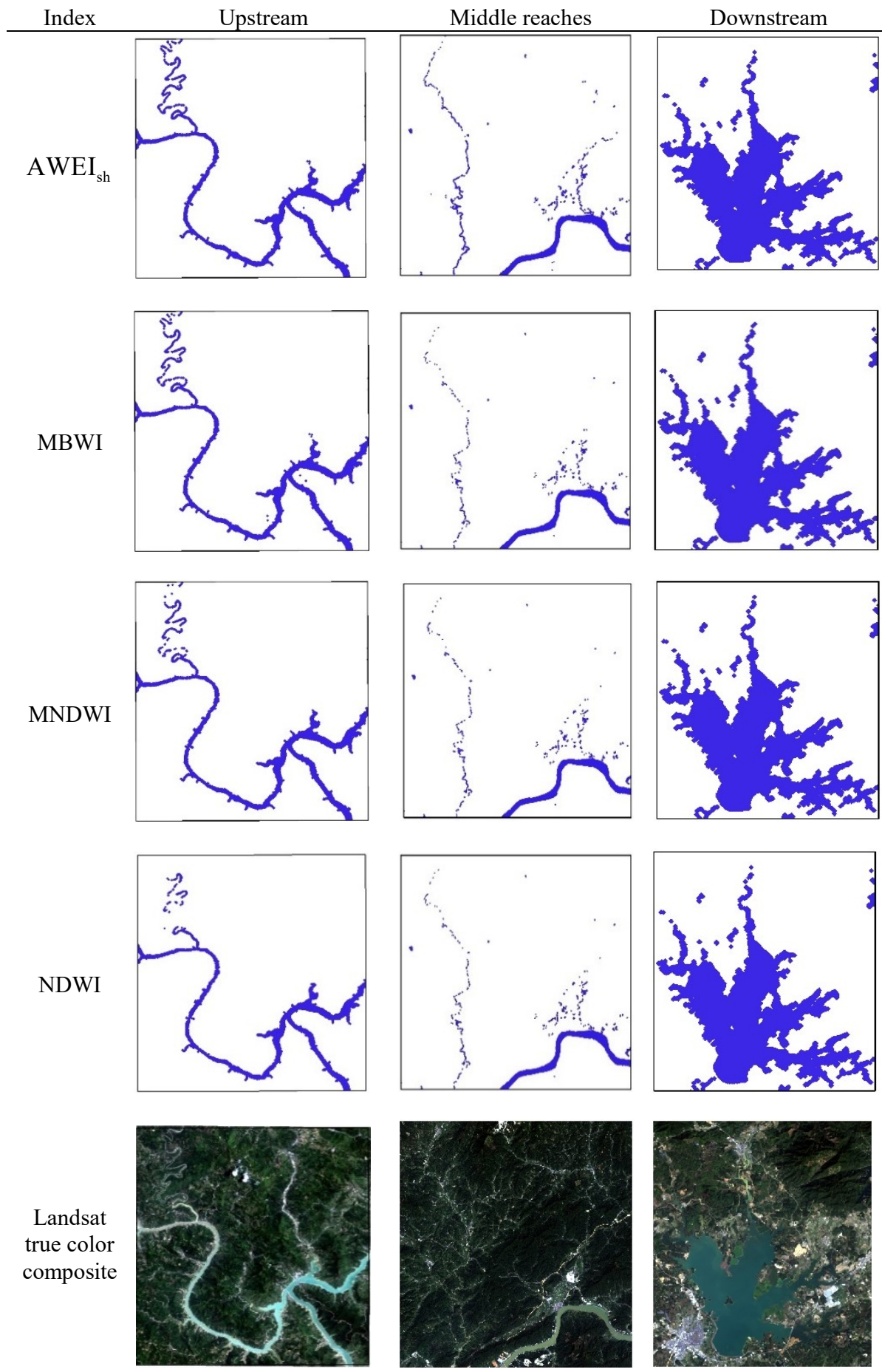

Figure 3. Water extraction images of different parts of the Pearl River Basin

\begin{tabular}{|c|c|c|c|c|c|}
\hline Index & $\begin{array}{c}\text { Overall } \\
\text { accuracy\% }\end{array}$ & $\begin{array}{c}\text { Kappa } \\
\text { coeff.\% }\end{array}$ & $\begin{array}{c}\text { water } \\
\text { commission } \\
\text { error\% }\end{array}$ & $\begin{array}{c}\text { water } \\
\text { omission } \\
\text { error\% }\end{array}$ & $\begin{array}{c}\text { water } \\
\text { total } \\
\text { error\% }\end{array}$ \\
\hline NDWI & 86.92 & 73.67 & 7.19 & 5.89 & 13.08 \\
\hline MNDWI & 91.5 & 82.93 & 5.23 & 3.27 & 8.5 \\
\hline MBWI & 92.81 & 85.63 & 5.88 & 1.31 & 7.19 \\
\hline AWEI & 94.12 & 88.24 & 1.96 & 3.92 & 5.88 \\
\hline
\end{tabular}


Table 2. Accuracy and errors of different water indexes

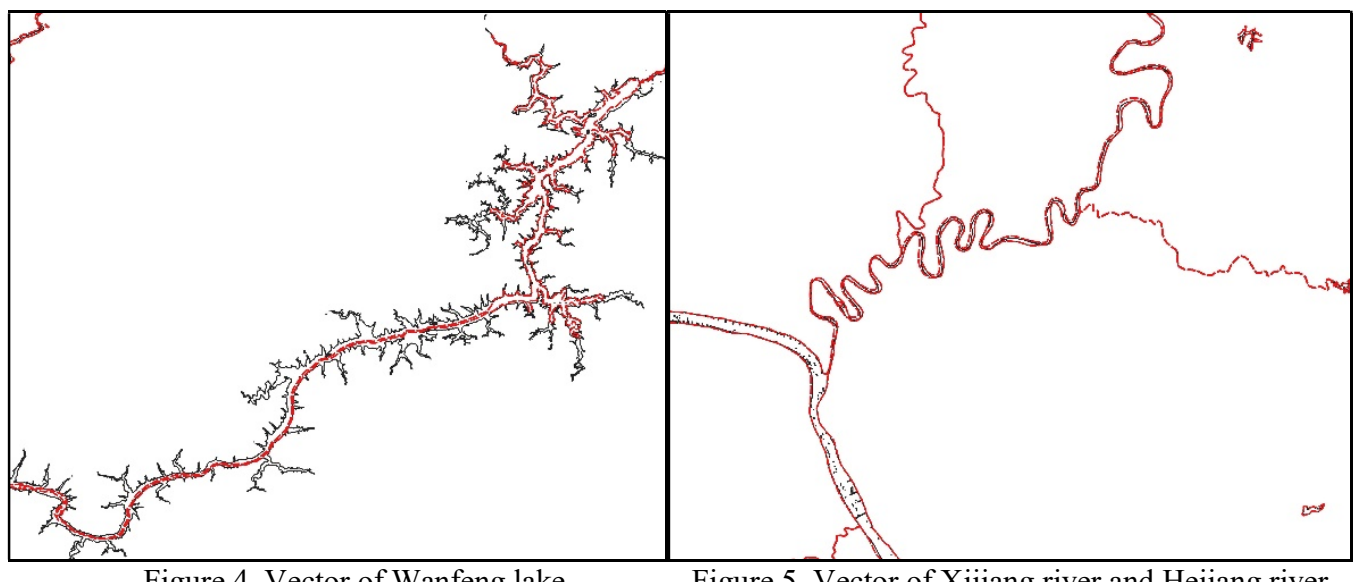

Figure 4. Vector of Wanfeng lake

Figure 5. Vector of Xijiang river and Hejiang river
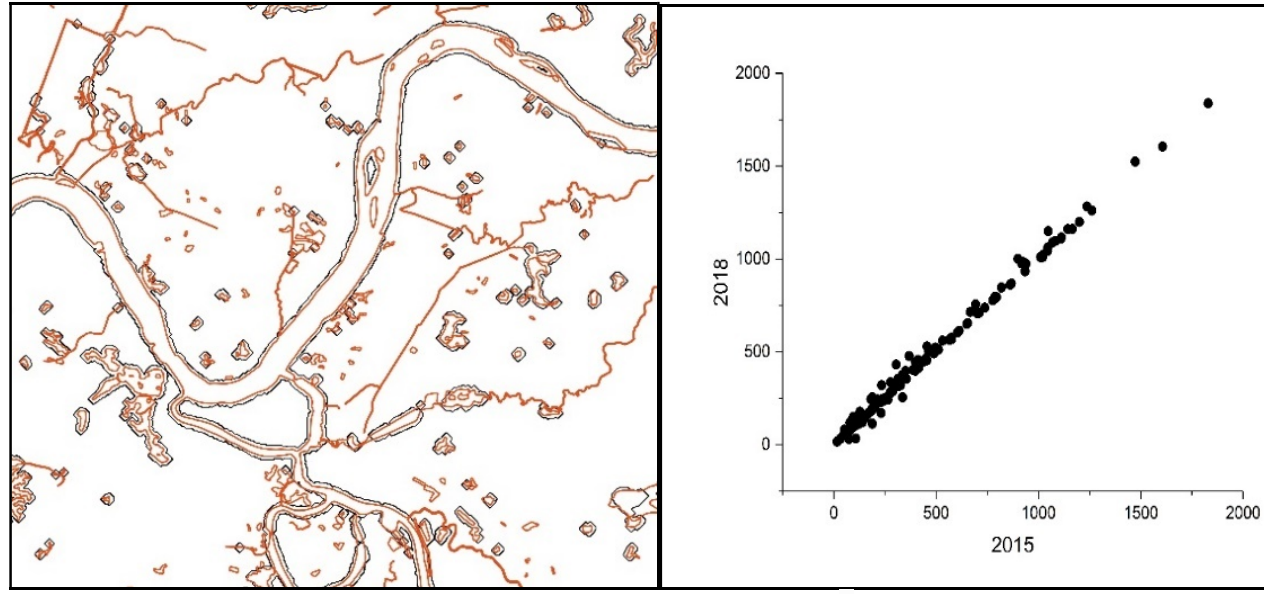

Figure 6. Vector of Dongjiang river and Xizhi river

\section{CONCLUSION}

The main purpose of this study is to extract surface water of the Pearl River Basin base on Google earth engine. By comparing the results of four water indexes after morphological postprocessing, it is shown that Google Earth Engine can extract surface water in a very short time, and $\mathrm{AWEI}_{\mathrm{sh}}$ is found to be superior to the other three water indexes with higher accuracy and smaller misclassification rate.

Comprehensive evaluation of the upper, middle and lower reaches of the Pearl River Basin. All four water body indices can extract surface water effectively, but $\mathrm{AWEI}_{\mathrm{sh}}$ shows more accurate in identifying surface water under small rivers and complex terrain, and the integrity of the rivers is relatively better. For planar water bodies, such as reservoirs and lakes, the results of four water index are basically the same. Qualitative evaluation of the rivers in the Pearl River Basin from 2015 to 2018 shows that the width of the rivers did not change much in the past three years, and the shape of the rivers remains basically stable.

\section{ACKNOWLEDGEMENTS}

This research is supported by the National Natural Science Foundation of China (No. 41801071), the Natural Science Foundation of Guangxi Province (No. 2018GXNSFBA281015), and the project supported by the Scientific Research start-up

\section{Foundation of Guilin University of Technology (GUTQDJJ2017096). \\ REFERENCES}

Xin Wang, SiqiuShen, Chen Ning, Fengchen Huang, HongminGao., 2016. Multi-class remote sensing objects recog-nition based on discriminative sparse representation. Applied Optics, 55(6): 1381-1394.

Acharya T D, Subedi A, Huang H, et al. , 2019. Application of Water Indices in Surface Water Change Detection Using Landsat Imagery in Nepal. Sens. Mater, 31: 1429-1447.

Bahrawi J A, Elhag M., 2019. Consideration of seasonal variations of water radiometric indices for the estimation of soil moisture content in Arid Environment in Saudi Arabia. APPLIED ECOLOGY AND ENVIRONMENTAL RESEARCH, 17(1): 285-303.

Fan Y D, Wu W, Wang W, et al., 2016. Research progress of disaster remote sensing in China. Journal of Remote Sensing, 20(5): 1170-1184.

Vishnu C L, Sajinkumar K S, Oommen T, et al., 2019Satellitebased assessment of the August 2018 flood in parts of Kerala, India. Geomatics, Natural Hazards and Risk, 10(1): 758-767. 
Dong J, Xiao X, Menarguez M A, et al., 2016. Mapping paddy rice planting area in northeastern Asia with Landsat 8 images, phenology-based algorithm and Google Earth Engine. Remote sensing of environment, 185: 142-154.

McFeeters S K., 1996. The use of the Normalized Difference Water Index (NDWI) in the delineation of open water features. International journal of remote sensing, 17(7): 1425-1432.

Han-Qiu X U., 2005. A study on information extraction of water body with the modified normalized difference water index (MNDWI). Journal of remote sensing, 5: 589-595.

Deng Z, Sun Y, Zhang K, et al.,2019. A water identification method basing on grayscale Landsat 8 OLI images. Geocarto International, 1-11.

Ogilvie A, Belaud G, Massuel S, et al.,2018. Surface water monitoring in small water bodies: potential and limits of multisensor Landsat time series. Hydrology and Earth System Sciences, 22(8): 4349.

Zhang M, Chen F, Tian B.,2018. An automated method for glacial lake mapping in High Mountain Asia using Landsat 8 imagery. Journal of Mountain Science, 15(1): 13-24.

Gorelick N, Hancher M, Dixon M, et al.,2017. Google Earth Engine: Planetary-scale geospatial analysis for everyone. Remote Sensing of Environment, 202: 18-27.

Sun Z, Xu R, Du W, et al., 2019. High-resolution urban land mapping in China from sentinel $1 \mathrm{~A} / 2$ imagery based on Google Earth Engine. Remote Sensing, 11(7): 752.

Pekel J F, Cottam A, Gorelick N, et al., 2016. High-resolution mapping of global surface water and its long-term changes. Nature, 540(7633): 418.

Chen B, Xiao X, Li X, et al.,2017. A mangrove forest map of China in 2015: Analysis of time series Landsat 7/8 and Sentinel-1A imagery in Google Earth Engine cloud computing platform. ISPRS Journal of Photogrammetry and Remote Sensing, 131: 104-120.

Hansen M C, Potapov P V, Moore R, et al.,2013. Highresolution global maps of 21 st-century forest cover change. science, 342(6160): 850-853.

Onisimo Mutanga,Lalit Kumar, 2019. Google Earth Engine Applications. Remote Sensing, 11(5): 591.

Sazib N, Mladenova I, Bolten J., 2018. Leveraging the google earth engine for drought assessment using global soil moisture data. Remote Sensing, 10(8): 1265.

Wang Z, Zhong R, Lai C, et al.,2018. Climate change enhances the severity and variability of drought in the Pearl River Basin in South China in the 21st century. Agricultural and forest meteorology, 249: 149-162.

Liu X, Liang X, Li X, et al.,2017. A future land use simulation model (FLUS) for simulating multiple land use scenarios by coupling human and natural effects. Landscape and Urban Planning, 168: 94-116.
Su C, Chen X., 2019. Covariates for nonstationary modeling of extreme precipitation in the Pearl River Basin, China. Atmospheric Research.

Liu B, Chen X, Lian Y, et al.,2013. Entropy-based assessment and zoning of rainfall distribution. Journal of hydrology, 490: $32-40$.

Ranasinghe R, Wu C S, Conallin J, et al., 2019. Disentangling the relative impacts of climate change and human activities on fluvial sediment supply to the coast by the world's large rivers: Pearl River Basin, China. Scientific reports, (1): 9236.

Wang X, Xie S, Zhang X, et al., 2018. A robust Multi-Band Water Index (MBWI) for automated extraction of surface water from Landsat 8 OLI imagery. International journal of applied earth observation and geoinformation, 68: 73-91.

Feyisa G L, Meilby H, Fensholt R, et al., 2014. Automated Water Extraction Index: A new technique for surface water mapping using Landsat imagery. Remote Sensing of Environment, 140: 23-35. 